\title{
DOWNSTAGING OF A RECTAL GASTROINTESTINAL STROMAL TUMOR BY NEOADJUVANT IMATINIB THERAPY ALLOWING FOR A CONSERVATIVE SURGICAL APPROACH
}

doi: 10.1590/S1807-59322009000800018

Gustavo dos Santos Fernandes, ${ }^{\mathrm{I}}$ Guilherme Cutait de Castro Cotti, ${ }^{\mathrm{I}}$ Daniela Freitas, ${ }^{\mathrm{I}}$ Raul Cutait, ${ }^{\mathrm{II}}$ Paulo M. Hoff, IIII

\section{INTRODUCTION}

Gastrointestinal stromal tumor (GIST) is a recently recognized pathology that originates from the interstitial cells of Cajal ${ }^{1}$ and is the most common mesenchymal neoplasm of the gastrointestinal tract. Although surgery is the only treatment available, it is only possible in approximately half of the cases ${ }^{2}$. This malignancy is characterized by a high risk of metastatic relapse, specifically in the liver and peritoneum. Imatinib mesylate, a tyrosine kinase inhibitor that inhibits c-kit signal transduction, is often used as a treatment for metastatic GIST.

Neoadjuvant therapy is defined as a treatment administered prior to the main (usually surgical) treatment for a particular neoplasm. It is used not only to eliminate circulating tumor cells but also to reduce the size of the tumor, thereby facilitating surgery and perhaps increasing the chance of organ preservation. Since imatinib results in significant tumor shrinkage in at least $50 \%$ of treated patients, ${ }^{3,4}$ its use as a neoadjuvant treatment is logical.

\section{CASE REPORT}

A 32-year-old man, otherwise fit and healthy, underwent medical evaluation for hematochezia lasting a month. A complete proctological examination revealed a bulge in the anterior rectal wall, approximately $5 \mathrm{~cm}$ above the dentate

\footnotetext{
${ }^{\text {I }}$ Hospital Sírio Libanês, Centro de Oncologia - São Paulo/SP, Brazil

II Department of Radiology, Faculdade de Medicina da Universidade de São Paulo - São Paulo/SP, Brazil

III Department of Oncology, Faculdade de Medicina da Universidade de São Paulo - São Paulo/SP, Brazil

Tel: 55613377.0281

Email: gustavo.onco@terra.com.br
}

line. The rectal mucosa was normal upon digital examination and rigid proctoscopy, which confirmed the rectal bulge. A complete colonoscopy was unremarkable except for the findings described in the proctological examination. Routine laboratory tests and tumor markers were normal $(\mathrm{CEA}=$ 0.6; CA 19-9 = 8.1). An MRI of the abdomen and pelvis demonstrated a well-demarcated solid pelvic mass $(9.3 \mathrm{~cm}$ x $8.3 \mathrm{~cm}$ x $6.5 \mathrm{~cm} ; 257 \mathrm{cc}$ ) (Figures 1 and 2) compressing the bladder, prostate and rectum. While the tumor appeared to have infiltrated the muscular wall of the rectum, no other unusual findings were observed. A chest X-ray was normal, but a transperineal CT-guided biopsy was positive for a GIST. After a multidisciplinary discussion regarding the known risk of incomplete surgical resection, the patient was treated with $400 \mathrm{mg} / \mathrm{d}$ imatinib mesylate for 6 weeks in order to reduce the size of the tumor and increase the likelihood of curative surgery. An MRI after 6 weeks of imatinib mesylate treatment demonstrated a marked reduction in tumor size $(6.3 \mathrm{~cm}$ x $5.6 \mathrm{~cm} \mathrm{x} 4.7 \mathrm{~cm} ; 86 \mathrm{cc}$ ) (Figure 1 and 2 ). The patient was maintained on imatinib mesylate for another 4 weeks, after which a second MRI revealed no further decrease in the size of the lesion, and the patient was referred for surgery.

The patient underwent laparoscopic-assisted resection of the rectal GIST with partial removal of the anterior rectal wall, which was reconstructed using a manual suture. Frozen sections of the margins were negative. Since the suture was located $3 \mathrm{~cm}$ above the dentate line, a temporary loop ileostomy was made. Pathological examination confirmed a GIST (CD117 positive, CD34 positive) that was $6.5 \mathrm{~cm} \mathrm{x}$ $5.0 \mathrm{~cm} \times 2.0 \mathrm{~cm}$ in size with a low mitotic rate. The patient's recovery was uneventful, and he was discharged on postoperative day 4 . He was advised to continue with imatinib mesylate treatment for another 9 months, completing one 


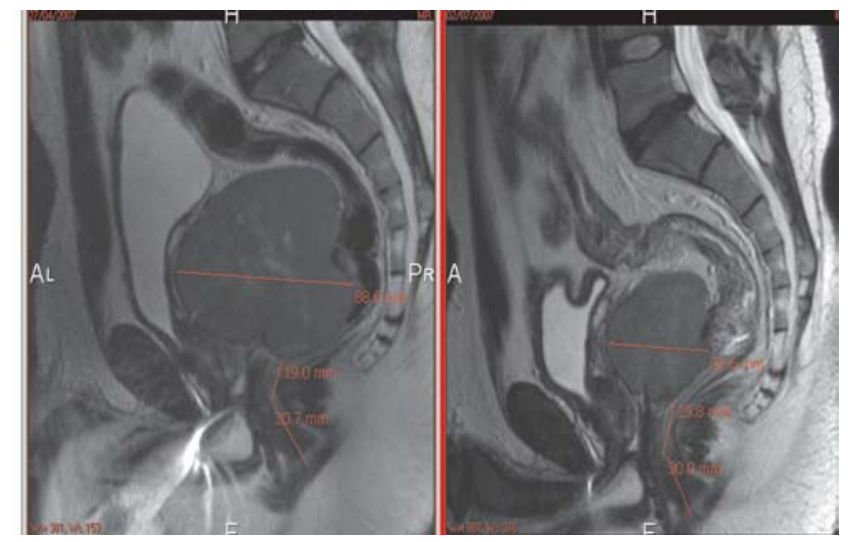

Figure1 - Pre- and post-treatment MRI (sagittal) illustrating the reduction in tumor size
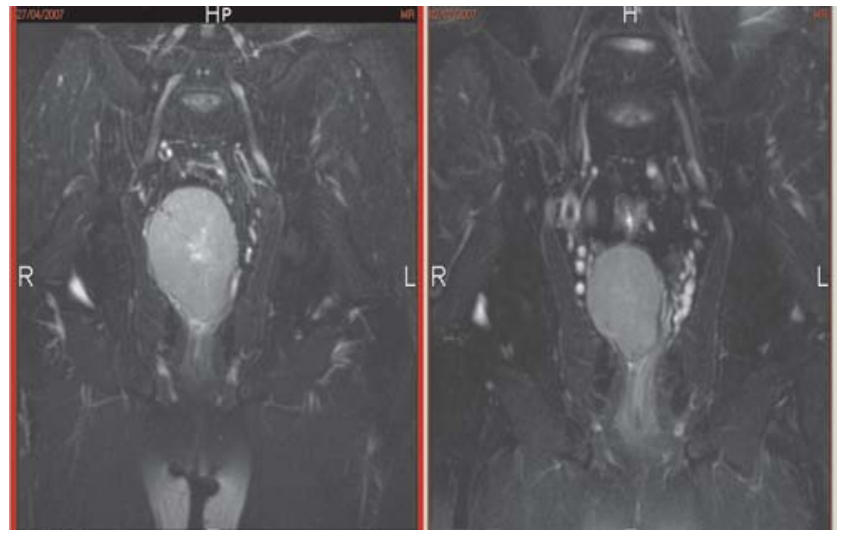

Figure 2 - Pre- and post-treatment MRI illustrating the reduction in tumor size

year of treatment. The loop ileostomy was closed 12 weeks after the tumor was removed with no complications.

\section{DISCUSSION}

GISTs can be unresectable or, as in our report, resectable tumors requiring extensive organ disruption in order to achieve complete resection. Therefore, the use of imatinib prior to surgical resectioning to reduce the tumor size is an attractive approach. Since 2003, several case reports regarding the use of neoadjuvant treatment for GIST have been published, and one phase II trial has been completed. The usual therapeutic regimen involves a course of imatinib, commonly administered for 3 to 12 months, with frequent imaging studies and a re-evaluation of the best time for surgery. The decision regarding the best time to operate, which should take into account both resectability and the maximum therapeutic effect remains controversial, particularly since tumor progression can occur rapidly even after a substantial tumor shrinkage. Progression of the tumor establishes a clinical dilemma: if radical salvage surgery is possible, it remains a reasonable therapeutic option as opposed to performing salvage systemic therapy, which would likely have little chance of achieving a substantial reduction in tumor size. Unfortunately, the long-term results for surgery performed on refractory tumors are typically worse. The resectioning of progressive disease appears to benefit only those patients with focal progression and has little to offer to those who experience generalized disease progression while receiving imatinib. ${ }^{5-9}$

The preliminary data suggesting the benefits of neoadjuvant treatment with imatinib were obtained in a phase II trial (RTGO 0132) carried out by the Radiation Therapy Oncology Group (RTOG). ${ }^{12}$ This study included patients with biopsy-proven GIST that was classified as either potentially resectable primary disease $(\geq 5 \mathrm{~cm})$ or potentially resectable locally recurrent or metastatic disease ( $\geq 2 \mathrm{~cm}$ ). Between February and June of 2006, 63 patients from 18 institutions were treated with imatinib $(600 \mathrm{mg}$ / day) for 8 to 12 weeks prior to surgical resection and two additional years of imatinib treatment. Among the 52 patients analyzed, 30 patients had locally advanced disease, and 22 patients had recurrent/metastatic disease. Surgery was performed in 45 of the 52 cases, and one patient died due to an infectious complication. A response to preoperatory imatinib (RECIST) was observed in 2 patients (7\%) with locally advanced disease and 25 patients $(83 \%)$ with stable disease. None of these tumors progressed during treatment. Within 2 years of the termination of treatment, the progression free survival and overall survival for those patients who presented with locally advanced disease were $82 \%$ and $93 \%$, respectively. This trial demonstrated that pre-operative treatment with imatinib is safe with minimal drug-related toxicity and surgical morbidity. The PFS and OS are favorable for this group with high-risk GIST. Despite these promising results, this strategy is currently not recommended for use outside of a clinical trial. The only reasonable exception would be the use of imatinib mesylate by an experienced multidisciplinary team when an objective response could result in organ preservation. 


\section{REFERENCES}

1. Fletcher CD, Berman JJ, Corless C, Gorstein F, Lasota J, Longley BJ, et al. Diagnosis of gastrointestinal stromal tumors: a consensus approach. Int J Surg Pathol. 2002;10:81-9.

2. DeMatteo RP, Lewis JJ, Leung D, Mudan SS, Woodruff JM, Brennan MF. Two hundred gastrointestinal stromal tumors: recurrence patterns and prognostic factors for survival. Ann Surg. 2002;31:51-8.

3. van Oosterom AT, Judson I, Verweij J, Stroobants S, Donato di Paola E, Dimitrijevic S, et al. Safety and efficacy of imatinib (STI571) in metastatic gastrointestinal stromal tumours: a phase I study. Lancet. 2001;358:1421-3.

4. Gold JS, Dematteo RP: Neoadjuvant therapy for gastrointestinal stromal tumor (GIST): racing against resistance. Ann Surg Oncol. 2007; 14:12478 .

5. Hasegawa J, Kanda T, Hirota S, Fukuda M, Nishitani A, Takahashi $\mathrm{T}$, et al. Surgical interventions for focal progression of advanced gastrointestinal stromal tumors during imatinib therapy. Int J Clin Oncol. 2007; $12: 212-7$.

6. DeMatteo RP, Maki RG, Singer S, Gonen M, Brennan MF, Antonescu CR. Results of tyrosine kinase inhibitor therapy followed by surgical resection for metastatic gastrointestinal stromal tumor. Ann Surg. 2007;245:347-52.

7. Rutkowski P, Nowecki Z, Nyckowski P, Dziewirski W, Grzesiakowska U, Nasierowska-Guttmejer A, et al. Surgical treatment of patients with initially inoperable and/or metastatic gastrointestinal stromal tumors (GIST) during therapy with imatinib mesylate. J Surg Oncol. 2006;93:304-11.
8. Raut CP, Posner M, Desai J, Morgan JA, George S, Zahrieh D, et al. Surgical management of advanced gastrointestinal stromal tumors after treatment with targeted systemic therapy using kinase inhibitors. J Clin Oncol. 2006;24:2325-31.

9. Al-Batran SE, Hartmann JT, Heidel F, Stoehlmacher J, Wardelmann $\mathrm{E}$, Dechow C, et al. Focal progression in patients with gastrointestinal stromal tumors after initial response to imatinib mesylate: a three-centerbased study of 38 patients. Gastric Cancer. 2007;10:145-52.

10. Blanke CD, Rankin C, Demetri GD, Ryan CW, von Mehren M, Benjamin $\mathrm{RS}$, et al. Phase III randomized, intergroup trial assessing imatinib mesylate at two dose levels in patients with unresectable or metastatic gastrointestinal stromal tumors expressing the kit receptor tyrosine kinase: S0033. J Clin Oncol. 2008;26:626-32.

11. Heinrich MC, Corless CL, Blanke CD, Demetri GD, Joensuu H, Roberts PJ, et al. Molecular correlates of imatinib resistance in gastrointestinal stromal tumors. J Clin Oncol. 2006;24:4764-74.

12. Eisenberg BL, Harris J, Blanke CD, Demetri GD, Heinrich MC, Watson JC, et al. Phase II trial of neoadjuvant/adjuvant imatinib mesylate (IM) for advanced primary and metastatic/recurrent operable gastrointestinal stromal tumor (GIST): early results of RTOG 0132/ACRIN 6665. J Surg Oncol. 2009;99:42-7. 